\title{
Phenolic quantification and botanical origin of Portuguese propolis
}

\author{
Soraia I. Falcão ${ }^{\mathrm{a}, \mathrm{b}}$, Andreia Tomás $^{\mathrm{a}}$, Nuno Vale ${ }^{\mathrm{c}}$, Paula Gomes ${ }^{\mathrm{c}}$, \\ Cristina Freire $^{\mathrm{b}}$, Miguel Vilas-Boas ${ }^{\mathrm{a}, *}$ \\ a CIMO - Escola Superior Agrária, Instituto Politécnico de Bragança, Campus de Santa Apolónia, Apartado 1172, 5301 -855 Bragança, Portugal \\ ${ }^{\mathrm{b}}$ REQUIMTE/Departamento de Química e Bioquímica, Faculdade de Ciências da Universidade do Porto, Rua do Campo Alegre, 4169-007 Porto, Portugal

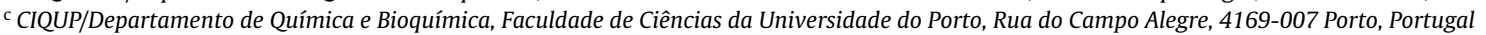

\section{A R T I C L E I N F O}

\section{Article history:}

Received 10 May 2013

Received in revised form 6 July 2013

Accepted 9 July 2013

\section{Keywords:}

Propolis

Phenolic quantification

Populus spp.

Cistus ladanifer

Geographical origin

Botanical origin

\begin{abstract}
A B S T R A C T
The production of propolis by honeybees results from a selective collection of exudates from leaf buds and plants present in the hive neighborhood leading to a resin with many potentialities in the pharmaceutical industry. This study aims to quantify the phenolic content in propolis from different Portuguese regions and in the potential floral sources, Populus $x$ Canadensis Moench buds and Cistus ladanifer L., in order to establish links with geographical and botanical origin.

The Portuguese propolis revealed a phenolic profile with marked differences in concentrations: the richness in flavonoids is common in all regions, but more evident in propolis from central interior, south and Madeira. The composition of poplar type propolis common in temperate zones was observed in the north, central coast and Azores, while the central interior and south samples, with a composition rich in kaempferol derivatives, resemble the $C$. ladanifer exudates, a spontaneous bush widespread in the Mediterranean. The compound kaempferol-3,7-dimethyl-ether, absent in the poplar type propolis, can be regard as a possible marker for the discrimination of these two types of propolis.
\end{abstract}

(c) 2013 Elsevier B.V. All rights reserved.

\section{Introduction}

The honeybee exploit nature as a store to fulfill its nutritional needs, collecting nectar and pollen, but also as a source for substances with other goals such as construction material or to maintain the antiseptic environment in the hive (Burdock, 1998; Bogdanov and Bankova, 2011). With the time evolution, bees were able to find in the surroundings of their nest the best source of materials for the desired proposes. Thus, it is not surprising the potentialities exhibit by propolis, a complex natural product gathered by the honeybees from resinous exudates of buds, leaves, branches and barks present in the vicinity of the beehive. Also named as the "bee glue" it plays an important role to guarantee the bee colony health.

Since ancient times, propolis is used in traditional medicine and now is gaining popularity in health foods as well in cosmetic products (Bogdanov and Bankova, 2011). A great number of research studies focused on the pharmacological and biological properties present by propolis, including antihepatotoxic, antitumor, antioxidative, antimicrobial, anti-inflammatory and immunomodulatory among others (Banskota et al., 2001; Bankova et al., 2000). These bioactivities are closely linked with the chemical composition, par-

\footnotetext{
* Corresponding author. Tel.: +351 273 303316; fax: +351273 325405 .

E-mail address: mvboas@ipb.pt (M. Vilas-Boas).
}

ticularly with the richness in phenolic compounds, which accounts for approximately half of the resin content, while beeswax, volatiles and pollen represents the other $30 \%, 10 \%$ and $5 \%$, respectively, of it. (Bogdanov and Bankova, 2011). The propolis chemical composition varies greatly with the plant origin of the resin and thus with the geographic and climatic characteristics of the site (Bankova, 2005). The specificity of local flora is very important, not all plants are resin providers and bees have a marked preference for one or a few sticky resin sources, which are, at the same time sources of biologically active phytochemicals (Salatino et al., 2011). Based on this knowledge, propolis was typified according to their plant origin and its main chemical constituents (Bankova, 2005). In temperate zones of the world, poplar buds (Populus spp.) are the main sources of the bee glue with flavones, flavanones, fenolic acids and their esters as major compounds. Exceptions can be found, for example, the birch propolis type found in Russia, which has its origin in species like Betula verrucosa, where the main compounds are flavones and flavonols different from those found in poplar propolis (Bankova, 2005). Also a Mediterranean propolis type was found in Sicily, Crete and Malta, whose main compounds are diterpenes most probably originated in coniferous plant of the genus Cupressaceae (Popova et al., 2009). Tropical propolis has a totally different compositional pattern: the green propolis type, found in Brazil, has its main plant source on the leaves of Baccharis spp. and mainly contains prenylated phenylpropanoids (Bankova et al., 2005). In Venezuela and Cuba, the main plant sources are the flower exudates of Clusia 
species, originating a propolis rich in prenylated benzophenones (Bankova et al., 2005). C-prenylflavonoids (or propolins) have been described in propolis from Pacific islands, where the resin sources are the fruit exudates of the tree Macaranga tanarius (Chen et al., 2003). The propolis typification on the basis of plant sources knowledge is a useful tool for its chemical standardization and thus for ensuring the quality and safety necessary for its commercialization (Bankova, 2005; Salatino et al., 2011).

Recently, the phenolic profile of Portuguese propolis was characterized by liquid chromatography with diode-array detection coupled to electrospray ionization tandem mass spectrometry (LC/DAD/ESI-MS ${ }^{n}$ ) (Falcão et al., 2013). Forty samples from different continental regions and islands were analyzed allowing the detection of seventy six polyphenols and the establishment of two different propolis groups: the common temperate propolis, which contained the typical poplar phenolic compounds such as flavonoids and their methylated/esterified forms, phenylpropanoid acids and their esters and an uncommon propolis type with an unusual composition in quercetin and kaempferol glycosides, some of them never described in propolis. The data suggest a diversified botanical origin for the Portuguese propolis besides poplar buds (Falcão et al., 2013).

Following those finds, we now present the phenolic quantification of propolis from the different Portuguese continental regions and islands. The results assort the compounds with major contribution to the propolis composition and allow the establishment of links with the geographical origin of this beehive product, a key factor for propolis commercial valorization. The inclusion of two potential floral sources of Portuguese propolis in this study, the buds exudates and surface material present on the leaves and stems of Populus $x$ Canadensis, male and female specimens and Cistus ladanifer $\mathrm{L}$. enable the correlation between the phenolic profile and the plant source of the resin, and the proposal of kaempferol3,7-dimethyl-ether as a marker compound for $C$. ladanifer propolis.

\section{Materials and methods}

\subsection{Chemicals and reagents}

Chrysin, quercetin, pinocembrin, caffeic acid, ferulic acid, caffeic acid phenylethyl ester (CAPE), salicylic acid were purchased from Sigma Chemical Co (St. Louis, MO, USA). Apigenin, kaempferol3-O-glucoside, kaempferol-3-O-rutinoside, acacetin were from Extrasynthese (Genay, France). Analytical grade formic acid and HPLC grade ethanol were obtained from Panreac (Barcelona, Spain). HPLC grade methanol and acetonitrile were purchased from LabScan (Lisbon, Portugal). Water was treated in a Milli-Q water purification system (Topway Global Inc., Houston, TX, USA).

\subsection{Samples origin}

The study was performed on propolis and plant present in the hive neighborhood and reported (Falcão et al., 2013; Martos et al., 1997) as propolis floral sources. Forty propolis samples were collected from six different geographical regions (Fig. S1) in Portugal continental north (N1-6, Bragança; N7, Miranda do Douro; N8, Mirandela; N9-10, Chaves; N11, Montalegre; N12-13, Boticas; N14, Barcelos); central interior (CI1, (Falcão et al., 2013) Guarda; CI2, Penamacor; CI3, Fundão; CI4, Nisa); central coast (CC1, Figueira da Foz; CC2, Leiria; CC3, Coruche; CC4, Ramada); south (S1-3, Aljezur; S4, Moncarapacho); Azores Archipelago (A1, Terceira Island; A2-11, S. Miguel Island); and from Madeira island (M1-3, Funchal, Madeira Island). Propolis sampling sites are located on the map provide in supplementary material (Fig. S1). All the samples were obtained between 2007 and 2009 after the honey harvesting season (July/September), by conventional scraping or through plastic screens.

For the floral sources of the bee glue we collect, in Bragança region, northeast Portugal, in the spring of 2009, the leaf-buds of Populus $x$ Canadensis Moenchen, male (PM) and female (PF) specimens and the leaves and stems of, $C$. ladanifer $(C)$. The voucher specimens are deposited at the herbarium of Escola Superior Agrária of Instituto Politécnico de Bragança with the reference number BRESA 5174, BRESA 5355 and BRESA 5356 for C, PF and $\mathrm{PM}$, respectively. All samples were stored at $-20^{\circ} \mathrm{C}$ until analysis.

\subsection{Phenolic compounds extraction}

Prior to the extraction, the resin available in the stems and leaves of Cistus specimens was scraped, grounded and homogenized. For Populus, the entire leaf-bud was grounded and homogenized. The phenolic extraction for propolis and for the floral sources was performed according with our previous work (Falcão et al., 2010) Briefly, $1 \mathrm{~g}$ of sample was mixed with $10 \mathrm{~mL}$ of $80 \%$ of ethanol/water and kept at $70^{\circ} \mathrm{C}$ for $1 \mathrm{~h}$. The resulting mixture was filtered and the residue was re-extracted in the same conditions. After the second extraction, the filtered solution was combined, concentrated, frozen at $-20^{\circ} \mathrm{C}$ and freeze-dried.

\section{4. $L C / D A D / E S I-M S^{n}$ analysis of the plant sources}

The LC/DAD/ESI-MS ${ }^{\mathrm{n}}$ analyses were performed on a Finnigan Surveyor Plus HPLC instrument equipped with a diode-array detector and coupled to a mass detector. The chromatographic and MS conditions used were described before (Falcão et al., 2013). The mass spectrometer used was a Finnigan Surveyor LCQ XP MAX quadrupolo ion trap mass spectrometer equipped with an ESI source. Control and data acquisition was carried out with Xcalibur ${ }^{\circledR}$ data system (ThermoFinnigan, San Jose, CA, USA).

\subsection{HPLC quantification}

The propolis and plant source extracts were analyzed by reversed-phase high-performance liquid chromatography (HPLC) with UV detection, according with our previous work (Falcão et al., 2010). Briefly, the chromatographic system consisted on a Knauer Smartline separation module equipped with a Knauer smartline autosampler 3800 , a cooling system set to $4{ }^{\circ} \mathrm{C}$ and a Knauer UV detector 2500. Data acquisition and remote control of the HPLC system was done by ClarityChrom ${ }^{\circledR}$ software (Knauer, Berlin, Germany). The column was a $250 \mathrm{~mm} \times 4 \mathrm{~mm}$ id, $5 \mu \mathrm{m}$ particle diameter, end-capped Nucleosil C18 (Macherey-Nagel) and its temperature was maintained at $30^{\circ} \mathrm{C}$. The mobile phase comprised (A) $0.1 \%$ formic acid in water and (B) $0.1 \%$ formic acid in acetonitrile, which were previously degassed and filtrated. The solvent gradient started with $80 \% \mathrm{~A}$ and $20 \% \mathrm{~B}$, reaching $30 \%$ B at $10 \mathrm{~min}, 40 \% \mathrm{~B}$ at $40 \mathrm{~min}, 60 \% \mathrm{~B}$ at $60 \mathrm{~min}, 90 \% \mathrm{~B}$ at $80 \mathrm{~min}$, followed by the return to the initial conditions. For the analysis, the ethanolic extract $(10 \mathrm{mg}$ ) was dissolved in $1 \mathrm{~mL}$ of $80 \%$ of ethanol. Salicylic acid, as the internal standard (IS), was added to all extracts. Each sample was filtered through a $0.2 \mu \mathrm{m}$ Nylon membrane (Whatman) and then $10 \mu \mathrm{l}$ of the solution was injected. Chromatographic data were acquired at $280 \mathrm{~nm}$.

Quantification was achieved using calibration curves for caffeic acid, ferulic acid, quercetin, pinocembrin, chrysin, and caffeic acid phenylethyl ester, obtained with seven concentration levels. When the standard was not available, the compound quantification was expressed in equivalent of the structurally closest phenolic compound. The calibration parameters are shown in Table 1. The linearity was investigated by calculation of the regression plots by the least squares method and expressed by the correlation 
Table 1

Calibration parameters for the phenolic acids and flavonoids used as standards ( $\mathrm{mg} / \mathrm{mL})$. The compound class to be quantified by each standard is also represented.

\begin{tabular}{|c|c|c|c|c|c|c|c|}
\hline Compound & Linearity range & Slope & Intercept & $R^{2}$ & $\mathrm{LOD}(\mathrm{mg} / \mathrm{mL})$ & $\mathrm{LOQ}(\mathrm{mg} / \mathrm{mL})$ & Group to be quantified \\
\hline Caffeic acid & $0.05-0.6$ & 22.3 & -0.2 & 0.9990 & 0.01 & 0.05 & Phenolic acids \\
\hline Ferulic acid & $0.04-0.6$ & 18.8 & -0.1 & 0.9993 & 0.01 & 0.04 & Methylated phenolic acids \\
\hline Quercetin & $0.05-2.0$ & 8.0 & -0.8 & 0.9999 & 0.02 & 0.05 & Flavonols \\
\hline Pinocembrin & $0.08-1.0$ & 16.2 & -0.2 & 0.9991 & 0.02 & 0.08 & Flavanones; dihydroflavonols \\
\hline Chrysin & $0.03-1.0$ & 23.0 & -1.0 & 0.9999 & 0.01 & 0.03 & Flavones \\
\hline CAPE & $0.06-1.0$ & 13.8 & -0.1 & 0.9996 & 0.02 & 0.06 & Phenolic acids esters \\
\hline
\end{tabular}

LOD = limit of detection; $L O Q=$ limit of quantification. $C A P E=$ caffeic acid phenethyl ester.

coefficient $\left(R^{2}\right)$. Concentrations of all compounds in propolis samples were calculated based on the peak area ratio. The limit of detection (LOD) and quantification (LOQ) were obtained from the $y$-intercept standard deviation $\left(S_{b}\right)$ and the slope $(m)$ of the calibration curve (Ribani et al., 2007), thus $\mathrm{LOD}=3 \times S_{b} / m$ and $\mathrm{LOQ}=10 \times S_{b} / m$.

\subsection{Statistics}

The statistic analysis was performed using SPSS version 18.0 program, and the hierarchical cluster was obtained with the Ward linkage method, using standardized variables.

\section{Results and discussion}

\section{1. $L C / D A D / E S I-M S^{n}$ analysis of the plant sources}

The chemical composition of the plant source determines the chemical profile of propolis, therefore the profile comparison is the best indicator for the evaluation of propolis origin. In the present work we explore the phenolic composition of two potential plant sources of Portuguese propolis. They were chosen due to its great abundance in the hive neighborhoods and to the empirical knowledge of local beekeepers, which frequently associate these plants as the resin source.

Poplar buds are described as the main source of propolis in temperate zones (Bankova et al., 2000). The analysis of poplar bud exudates from Populus nigra and Populus balsamifera showed in their composition terpenoids, phenolic acids and their esters, flavonoid aglycons and their chalcones (Greenaway et al., 1989; Isidorov and Vinogorova, 2003) with a different degree of complexity depending on the specie. Populus $x$ Canadensis is a hybrid poplar very common in Portugal and consequently a potential source of resin for honeybee, to our knowledge, not yet described.

For elucidation of its phenolic profile we collected the buds of male (PM) and female specimens (PF) in the neighborhood of the hives and analyzed by LC/DAD/ESI-MS ${ }^{n}$ in the negative ion mode as reported previously (Falcão et al., 2013), which allowed the elucidation of phenolic compounds by comparison of their chromatographic behavior, UV spectra and MS information, to those of reference compounds. When standards were not available, the structural information was confirmed with UV data combined with MS fragmentation patterns previously reported in the literature. Both PM and PF ethanolic extracts presented a phenolic profile similar to the one observed in Portuguese common temperate propolis type earlier described (Falcão et al., 2013). The composition is rich in phenolic acids and their derivatives, mainly caffeic acid, 3,4-dimethyl-caffeic acid, caffeic acid isoprenyl ester and its isomer, caffeic acid benzyl ester and caffeic acid phenylethyl ester. Also flavonoids and its derivatives were found in the PM and PF extracts, with pinocembrin, chrysin, pinobanksin-3-O-acetate and galangin as major compounds. Comparing the two genders, some differences were found: the female poplar presented the compounds pinobanksin5-methyl-ether-3-O-pentanoate, 3-hydroxy-5-methoxyflavanone,
pinobanksin-3-O-butyrate, pinobanksin-3-O-pentenoate, pinobanksin-3-O-pentanoate, pinobanksin-3-O-hexanoate, which were previously described in Portuguese propolis (Greenaway et al., 1989; Isidorov and Vinogorova, 2003) and were absent from the male poplar phenolic profile.

C. ladanifer is a spontaneous shrubby plant widespread in the Mediterranean region (Chaves et al., 1998). Local beekeepers associate this material with propolis due to its abundance near the hives but also based on the typical odor of Cistus spp. that can be identified in some samples. The secretions on the surface of the leaves and stems of $C$. ladanifer were collected, extracted and analyzed by $\mathrm{LC} / \mathrm{DAD} / \mathrm{ESI}-\mathrm{MS}^{\mathrm{n}}$. The representative chromatogram at $280 \mathrm{~nm}$ is shown in Fig. 1. This procedure allowed the detection of six flavonoids, mainly kaempferol derivatives (Table 2 ). These included kaempferol-3-O-glucoside (1), kaempferol-methyl-ether (4) and kaempferol-dimethyl-ether (6), of which the last two were recently described in propolis (Falcão et al., 2013). For a better assignment of the methyl positions on the flavonoid skeleton, a deeper look was made on the UV and MS data of the kaempferol-dimethyl-ether. The spectrum of this compound present maximum absorption bands II and I at 265 and $346 \mathrm{~nm}$, respectively. Comparing with the spectral data of kaempferol $(265,364 \mathrm{~nm})$, the introduction of methyl ethers on the free hydroxyls groups undergoes a hypsochromic shift of $18 \mathrm{~nm}$ in band I accompanied with a relative drop in the intensity, indicating a 3-O-methylation. This remarkable difference is generally used as a diagnostic tool in the identification of free hydroxyls at the $\mathrm{C}-3$ position of the flavonoid molecule, since the methylation in other positions has little effect on the absorption spectrum (Santos-Buelga et al., 2003). The other methyl ether group may be in C-7, C-5 or C-4' position. The introduction of more methyl ethers on the hydroxyls of the kaempferol increases lipophilicity and thus the retention time. Depending on the position of the methyl ether, the effect on the retention time is different, being the introduction on the C-7 and C-4' position less polar than the $\mathrm{C}-5$, since the internal hydrogen bond between the hydroxyl and the carbonyl at C-4 position is no longer possible and thus retention time decreases (Santos-Buelga et al., 2003). For the compound under discussion the retention time is higher than kaempferol, therefore the $\mathrm{C}-5$ position for the second methyl group can be disregarded. The fragmentation pattern of the product ion $m / z 313$ produced the ion at $m / z 298$ arising from the loss of methyl radical from the deprotonated molecular ion, as the most prominent fragment. A minor fragment of $m / z 165$ was also identified which was resultant from the retro Diels-Alder mechanism, indicating the presence of the methyl group in C-7 position (Cuyckens and Claeys, 2004). So, the compound was tentatively identified as kaempferol-3,7dimethyl-ether, nevertheless for an unequivocal determination of the group location, further structural studies with NMR are necessary. The flavonoid 5,3'-dihydroxy-3,7,4',5'-tetramethoxyflavone observed in the composition of Tunisian propolis and assigned by Martos et al. (1997) to the leaf exudates of Cistus spp. was not here identified. We cannot judge, however, if this difference arises from the different extraction procedure used or from the geographical origin, or to the botanical specie, since no reference is given concerning the Cistus specie evaluated on that work. Besides these 


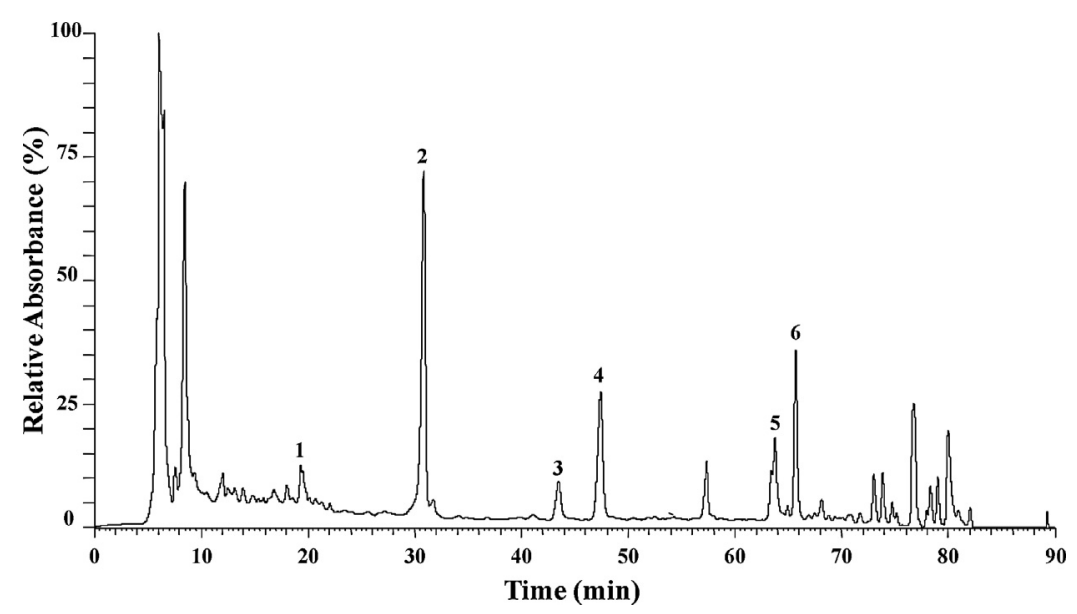

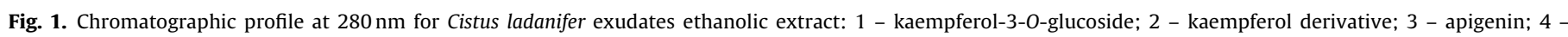
kaempferol-methyl-ether; 5 - acacetin; and 6 - kaempferol-3,7-dimethyl-ether.

compounds, a kaempferol derivative (2) was identified without the total elucidation of its structure. The ESI-MS² data obtained for its $[\mathrm{M}-\mathrm{H}]^{-}$ion at $\mathrm{m} / \mathrm{z} 593$ presented a base peak product ion at $\mathrm{m} / \mathrm{z}$ 285 with a fragmentation pattern similar to that of kaempferol, and a mass loss of $308 \mathrm{Da}$. Although this loss could correspond to a rutinoside, the elution time is greater than for the commercial standard and the UV spectrum show deviations from that of kaempferol aglycone, with the band I enhanced in intensity and shifted back to 313 (Table 2). These results could indicate an acylation by an aromatic acid in the molecule (Santos-Buelga et al., 2003). For the elucidation of the structure, further structural studies by NMR are required. Additionally, two flavones were identified, namely apigenin (3) and acacetin (5), which were present in the propolis samples (Falcão et al., 2013). This flavonoid pattern in the C. ladanifer exudates is consistent to the one described by Chaves et al. (1998) with a composition rich in apigenin and kaempferol derivatives.

\subsection{Phenolic quantification in propolis - geographical origin}

The phenolic complexity of propolis is linked with the phenolic diversity within a plant resin but also due to the combination of many different plants visited by the honeybees, particularly in sites with phyto-geographic diversity. Not all the resin sources or phenolic compounds within a resin are, however, in the propolis composition at significant amounts. In fact, some compounds are sometimes detected only as trace elements, which mean that the plant is scarce around the hive or it is not the honeybee preferred plant. For a better understanding of the phyto-diversity impact in the Portuguese propolis, we quantified the phenolic composition of forty samples, from different Portuguese geographical locations, using HPLC. The former evaluation of the phenolic profile of the samples (Falcão et al., 2013, 2010) allowed the detection of seventy-six phenolic compounds, including an uncommon group of flavonoid glycosides rarely described in this type of bee product (Falcão et al., 2013). From the overall list, only forty-one compounds were herein detected above the limit of quantification. Fig. 2a and b shows the experimental chromatograms for the commercial standards used in the quantification and for a typical propolis sample, respectively. Due to the number of compounds in the propolis chromatographic profile we decided to use in the quantification procedure a reduced number of phenolic compounds, representative of each class: caffeic acid, ferulic acid, caffeic acid phenylethyl ester, quercetin, pinocembrin and chrysin. For those compounds that do not fit under the chosen standards, the quantification was made in equivalents terms using the phenolic compound of the same chemical class (Table 1). Salicylic acid was chosen as internal standard, considering the detector response and the retention time, which did not interfere with the compounds under investigation. The analytical method exhibits a good linear response for all compounds, with correlation coefficients $\left(R^{2}\right)$ above 0.999 , and good sensitivity with the LOD varying between 0.01 and $0.02 \mathrm{mg} / \mathrm{mL}$ and LOQ varying from 0.03 and $0.08 \mathrm{mg} / \mathrm{mL}$ (Table 1).

The majority of the propolis samples presented a similar phenolic profile, but with marked differences in their concentrations. For an easier interpretation of the results, the individual compounds were aggregated in phenolic classes, as shown in Table 3, however the individual phenolic concentration and the MS fragmentation pattern can be found in the supplementary material (Table S1-S5). In all the regions, flavonoids were more abundant than simple phenolics (Fig. 3a) with pinocembrin, chrysin, pinobanksin-3-Oacetate and galangin as major compounds. The difference between these two phenolic groups is even more evident in samples from

Table 2

Flavonoids identified by LC/DAD/ESI-MS ${ }^{\mathrm{n}}$ in Cistus ladanifer exudates.

\begin{tabular}{|c|c|c|c|c|c|}
\hline $\mathrm{Nr}$ & $t_{\mathrm{R}}(\min )$ & $\lambda_{\max }(\mathrm{nm})$ & {$[\mathrm{M}-\mathrm{H}]^{-} m / z$} & MS $^{n}$ (\% base peak) & Compound \\
\hline 1 & 19.3 & 265,331 & 447 & $\operatorname{MS}^{2}[447]: 284$ (100), 285 (66) & Kaempferol-3-O-glucoside ${ }^{a}$ \\
\hline 2 & 30.9 & 265,313 & 593 & $\mathrm{MS}^{2}[593]: 285$ & Kaempferol derivative $\mathrm{b}^{\mathrm{b}}$ \\
\hline 3 & 43.4 & 268,337 & 269 & MS $^{2}$ [269]: 225 (100), 151 (69) & Apigenin ${ }^{\mathrm{a}}$ \\
\hline 4 & 47.4 & 265,352 & 299 & $\mathrm{MS}^{2}[299]: 284$ & Kaempferol-methyl-ether ${ }^{\mathrm{b}, \mathrm{c}}$ \\
\hline 5 & 63.7 & 268,331 & 283 & $\mathrm{MS}^{2}[283]: 269$ & Acacetin $^{\mathrm{a}}$ \\
\hline 6 & 65.7 & 265,346 & 313 & $\begin{array}{l}\operatorname{MS}^{2}[313]: 299(10), 298(100), 165(<1) \\
\text { MS }^{3}[298]: 283(100), 269(8), 255(41), 241(2) \\
\text { MS }^{4}[283]: 255(100), 151(<1)\end{array}$ & Kaempferol-3,7-dimethyl-ether ${ }^{\mathrm{b}, \mathrm{c}}$ \\
\hline
\end{tabular}

\footnotetext{
a Confirmed with standard.

b Confirmed with MS ${ }^{\mathrm{n}}$ fragmentation.

c Confirmed with reference (Falcão et al., 2013).
} 
Table 3

Composition of phenolic classes present in Portuguese propolis and its plant sources ( $\mathrm{mg} / \mathrm{g}$ of extract).

\begin{tabular}{|c|c|c|c|c|c|c|c|c|c|c|}
\hline Sample & $\begin{array}{l}\text { Phenolic } \\
\text { acids }\end{array}$ & $\begin{array}{l}\text { Phenolic } \\
\text { esters }\end{array}$ & $\begin{array}{l}\text { Total } \\
\text { simple } \\
\text { phenolics }\end{array}$ & Flavonols & Flavones & Dihydroflavonols & Flavanones & $\begin{array}{l}\text { Flavonoid } \\
\text { esters }\end{array}$ & $\begin{array}{l}\text { Flavonoid } \\
\text { glycosides }\end{array}$ & $\begin{array}{l}\text { Total } \\
\text { flavonoids }\end{array}$ \\
\hline \multicolumn{11}{|l|}{ Propolis } \\
\hline $\mathrm{N} 1$ & 95.5 & 161.0 & 256.5 & 102.9 & 94.83 & 35.9 & 74.6 & 150.2 & nd & 458.4 \\
\hline $\mathrm{N} 2$ & 39.6 & 115.1 & 154.7 & 109.5 & 98.41 & 36.3 & 73.3 & 102.2 & nd & 419.7 \\
\hline N3 & 53.6 & 157.2 & 210.8 & 92.2 & 70.99 & 23.5 & 45.9 & 67.7 & nd & 300.2 \\
\hline N4 & 72.1 & 118.2 & 190.3 & 114.7 & 86.45 & 47.3 & 64.0 & 147.7 & nd & 460.0 \\
\hline N5 & 44.3 & 100.7 & 145.0 & 81.1 & 63.41 & 26.9 & 53.8 & 80.9 & nd & 306.2 \\
\hline N6 & 35.3 & 84.7 & 120.1 & 45.4 & 38.36 & 18.2 & 43.4 & 76.3 & nd & 221.6 \\
\hline N7 & 47.1 & 98.1 & 145.2 & 90.6 & 66.01 & 22.3 & 46.4 & 71.3 & nd & 296.6 \\
\hline N8 & 40.9 & 93.2 & 134.1 & 112.2 & 84.37 & 39.0 & 93.4 & 128.3 & nd & 457.3 \\
\hline N9 & 83.5 & 32.3 & 115.9 & 68.7 & 36.39 & 47.8 & 25.4 & 25.1 & nd & 203.4 \\
\hline N10 & nq & 76.8 & 76.8 & 62.5 & 60.26 & 6.8 & 27.7 & 55.1 & nd & 212.3 \\
\hline N11 & 12.9 & 28.1 & 41.1 & 49.1 & 35.65 & 3.6 & 8.3 & 12.4 & 23.2 & 132.1 \\
\hline N12 & 1.5 & 6.4 & 8.0 & 47.1 & 30.16 & 2.7 & 7.8 & 9.6 & 12.6 & 109.9 \\
\hline N13 & 1.0 & $\mathrm{nq}$ & 1.0 & 45.5 & 19.49 & 1.9 & nq & 1.5 & 19.4 & 87.8 \\
\hline N14 & 89.9 & 171.4 & 261.3 & 55.9 & 74.97 & 61.2 & 55.5 & 42.6 & nd & 290.2 \\
\hline CI1 & 43.6 & $\mathrm{nq}$ & 43.6 & 167.8 & 96.22 & 10.6 & 17.9 & 14.4 & 227.7 & 534.6 \\
\hline $\mathrm{Cl} 2$ & $\mathrm{nq}$ & $\mathrm{nq}$ & $\mathrm{nq}$ & 50.2 & 20.59 & 2.0 & nq & nq & nd & 72.8 \\
\hline $\mathrm{CI} 3$ & 4.9 & 19.8 & 24.7 & 123.3 & 35.19 & 4.5 & 24.9 & 16.0 & nd & 203.9 \\
\hline $\mathrm{CI} 4$ & 15.5 & 27.1 & 42.6 & 99.9 & 33.12 & 5.5 & 15.9 & 25.7 & nd & 180.1 \\
\hline CC1 & 58.4 & 91.8 & 150.1 & 79.3 & 53.39 & 50.1 & 53.4 & 90.4 & nd & 326.6 \\
\hline $\mathrm{CC} 2$ & 30.4 & 36.4 & 66.9 & 100.8 & 50.85 & 75.2 & 60.1 & 96.6 & nd & 383.5 \\
\hline CC3 & 59.7 & 97.7 & 157.4 & 85.2 & 62.70 & 24.4 & 52.5 & 72.8 & nd & 297.6 \\
\hline CC4 & 24.9 & 103.1 & 128.0 & 100.7 & 71.55 & 23.3 & 60.5 & 94.3 & nd & 350.4 \\
\hline S1 & 42.5 & 88.3 & 130.8 & 99.6 & 74.48 & 38.4 & 61.4 & 91.9 & nd & 365.8 \\
\hline S2 & nq & $\mathrm{nq}$ & $\mathrm{nq}$ & 90.4 & 22.21 & 4.0 & $\mathrm{nq}$ & $\mathrm{nq}$ & nd & 116.6 \\
\hline S3 & nq & $\mathrm{nq}$ & nq & 121.1 & 24.56 & 6.2 & nq & nq & nd & 151.9 \\
\hline S4 & 36.8 & 6.8 & 43.6 & 82.3 & 22.41 & 2.7 & nq & nq & 11.5 & 118.9 \\
\hline $\mathrm{A} 1$ & 51.8 & 129.8 & 181.6 & 99.1 & 84.48 & 33.2 & 64.0 & 88.5 & nd & 369.3 \\
\hline $\mathrm{A} 2$ & 67.5 & 171.7 & 239.3 & 56.2 & 67.73 & 11.9 & 36.4 & 65.1 & nd & 237.4 \\
\hline A3 & 56.4 & 130.8 & 187.2 & 41.4 & 63.43 & 11.4 & 45.0 & 50.2 & nd & 211.5 \\
\hline A4 & 47.9 & 110.0 & 157.9 & 39.8 & 52.87 & 10.3 & 38.9 & 41.4 & nd & 183.2 \\
\hline A5 & 55.0 & 98.4 & 153.4 & 40.6 & 47.66 & 10.8 & 32.9 & 43.2 & nd & 175.1 \\
\hline A6 & 63.5 & 142.6 & 206.1 & 47.7 & 59.54 & 10.7 & 39.2 & 63.0 & nd & 220.1 \\
\hline A7 & 60.9 & 139.9 & 200.8 & 55.4 & 53.08 & 10.3 & 31.8 & 56.1 & nd & 206.6 \\
\hline A8 & 35.8 & 85.4 & 121.2 & 50.7 & 45.44 & 7.8 & 25.3 & 44.1 & nd & 173.3 \\
\hline A9 & 38.5 & 73.7 & 112.3 & 52.1 & 48.84 & 12.5 & 30.2 & 47.2 & nd & 190.9 \\
\hline A10 & 52.7 & 92.2 & 144.8 & 56.7 & 47.70 & 13.1 & 25.9 & 20.9 & nd & 164.3 \\
\hline A11 & 60.0 & 123.2 & 183.2 & 82.6 & 69.36 & 23.6 & 40.5 & 31.7 & nd & 247.7 \\
\hline M1 & nq & nq & $\mathrm{nq}$ & nd & 14.15 & nd & $\mathrm{nq}$ & nq & nd & 14.1 \\
\hline M2 & $\mathrm{nq}$ & nq & nq & 91.4 & 4.64 & 8.4 & nq & nd & 14.7 & 119.1 \\
\hline M3 & 64.2 & 28.4 & 92.6 & 61.0 & 25.22 & 8.6 & 32.1 & 34.1 & nd & 160.9 \\
\hline \multicolumn{11}{|c|}{ Plant sources } \\
\hline PM & 29.1 & 59.1 & 88.2 & 41.8 & 35.38 & 6.0 & 21.5 & 23.4 & nd & 128.1 \\
\hline $\mathrm{PF}$ & 29.4 & 64.5 & 93.8 & 30.9 & 46.95 & 3.8 & 36.8 & 41.7 & nd & 160.1 \\
\hline C & nd & nd & nd & 26.9 & 10.57 & nd & nd & nd & 27.4 & 64.8 \\
\hline
\end{tabular}

nq - not quantified; nd - not detected.

central interior, south and Madeira Island, where flavonoids represented more than $85 \%$ of the total phenolic content.

The contribution of the individual chemical classes was not identical for each region: for the simple phenolics, the esters derivatives were more abundant than the corresponding acid compounds, with the propolis from north $(\mathrm{N})$ of Portugal and Azores Archipelago (A) revealing the highest content, with 89 and $117 \mathrm{mg} / \mathrm{g}$, respectively (Fig. 3b). Samples from the central interior region, south and Madeira Island were exceptions, with an evident low content in simple phenolics, where phenolic acids were prevailing.

The flavonoid content was also distinct between regions and highly abundant in propolis from the north $(\mathrm{N})$ and central coast (CC) (Fig. 3c), although some samples can be seen as outliers in their region, particularly those from central interior CI1 with a abnormal high content, $534.6 \mathrm{mg} / \mathrm{g}$ and the samples N11-N13 from north, CI2 from central interior, S2 and S4 from south and M1-M2 from Madeira island, with values below $132 \mathrm{mg} / \mathrm{g}$ of extract (Table 3). Looking at each individual flavonoid sub-classes, the concentrations profile changed between regions, which must stem from the different vegetation sources around the hive: in the north $(\mathrm{N})$, central coast $(\mathrm{CC})$ and Azores (A), propolis was richer in flavonols, flavones and flavonoid esters, while on the south $(\mathrm{S})$ and in Madeira (M) the propolis flavonoid composition was mainly flavonols (above 50\%). The propolis from the central interior (CI) fitted on a different level due to the huge presence of flavonoid glycosides, observed also in the north $(\mathrm{N})$, south $(\mathrm{S})$ and Madeira (M) but only at very low concentration (Fig. 3c).

The flavonols concentration varied from the highest average value of $110 \mathrm{mg} / \mathrm{g}$ found in the central interior $(\mathrm{CI})$ to $51 \mathrm{mg} / \mathrm{g}$ in Madeira (M) propolis. With exception of propolis from Azores (A), this class was the most relevant for the total flavonoid content $(25 \%$ in Azores to 52\% in the south).

The contribution of flavones was also very significant in the north $(\mathrm{N})$, central coast $(\mathrm{CC})$ and Azores (A) propolis ranging from a maximum of $61 \mathrm{mg} / \mathrm{g}$ in the north (22\%) down to a minimum of $15 \mathrm{mg} / \mathrm{g}$ in Madeira propolis (15\%), Table 3. In Azores (A), the flavones content in propolis was even higher than flavonols (Fig. 3c).

Dihydroflavonols did not played the same role in the propolis flavonoid composition and its input can be down to $2 \%$ in samples from the central interior $(\mathrm{CI})$. The maximum amount was observed 

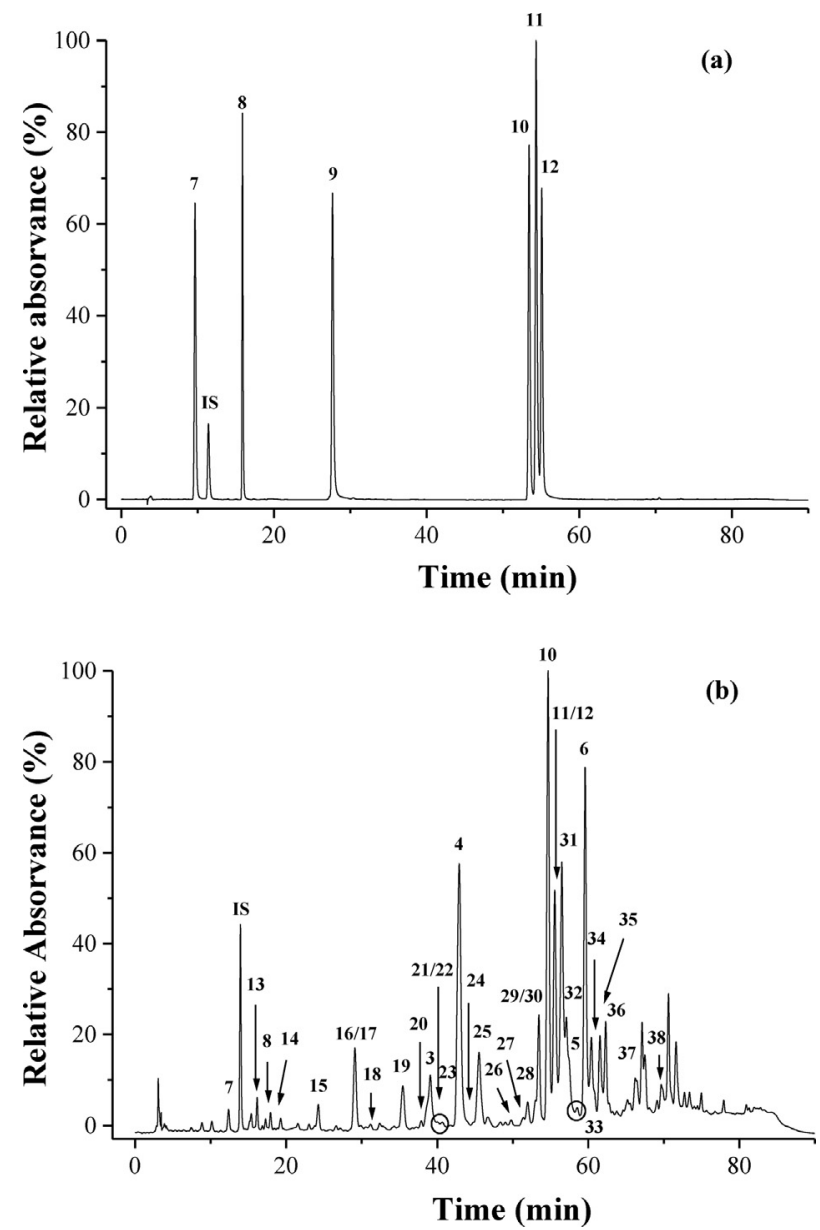

Fig. 2. Chromatographic profiles at $280 \mathrm{~nm}$. (a) Standards compounds: 7 - caffeic acid $(0.2 \mathrm{mg} / \mathrm{mL})$; IS - internal standard (salicylic acid; $0.2 \mathrm{mg} / \mathrm{mL}$ ); 8 - ferulic acid $(0.2 \mathrm{mg} / \mathrm{mL}) ; 9$ - quercetin $(0.6 \mathrm{mg} / \mathrm{mL}) ; 10$ - pinocembrin $(0.3 \mathrm{mg} / \mathrm{mL}) ; 11$ chrysin $(0.3 \mathrm{mg} / \mathrm{mL}) ; 12$ - caffeic acid phenylethyl ester $(0.3 \mathrm{mg} / \mathrm{mL})$. (b) Propolis ethanolic extract of sample CI3 $(10 \mathrm{mg} / \mathrm{mL}): 7$ - caffeic acid; IS - internal standard (salicylic acid); 13 - p-coumaric acid; 8 - ferulic acid; 14 - isoferulic acid; 15 - 3,4dimethyl-caffeic acid; 16 - pinobanksin-5-methyl-ether; 17 - cinnamic acid; 18 p-coumaric acid methyl ester; 19 - pinobanksin; 20 - pinocembrin-5-methyl-ether; 3 - apigenin; 21 - chrysin-5-methyl-ether; 22 - kaempferol; 23 - isorhamnetin; 4 - kaempferol-methyl-ether; 24 - quercetin-dimethyl-ether; 25 - cinnamyldenacetic acid; 26 - rhamnetin; 27 - quercetin-dimethyl-ether (isomer); 28 - caffeic acid isoprenyl ester; 29 - caffeic acid isoprenyl ester (isomer); 30 - caffeic acid benzyl ester; 10 - pinocembrin; 11 - chrysin; 12 - caffeic acid phenylethyl ester; 31 - pinobanksin-3-0-acetate; 32 - galangin; 5 - acacetin; 33 - chrysin-6-methylether; 6 - kaempferol-3,7-dimethyl-ether; 34 - p-coumaric acid isoprenyl ester; 35 caffeic acid cinnamyl ester; 36 - pinobanksin-3-O-propionate; 37 - pinobanksin-3$O$-butyrate or isobutyrate; 38 - pinobanksin-3-O-pentanoate or 2-methylbutyrate.

in the samples from the north $(\mathrm{N})$ and coast center (CC), but never above $13 \%$ ( $43 \mathrm{mg} / \mathrm{g})$.

In this study, only two flavanones were detected, pinocembrin5-methyl-ether (20) and pinocembrin (6), and only the last one was quantifiable. The generality of samples from north $(\mathrm{N})$ and coast center (CC) showed a high content in pinocembrin, $25-93 \mathrm{mg} / \mathrm{g}$ and $52-61 \mathrm{mg} / \mathrm{g}$ of extract, respectively (Table 3 ). Exceptions within the north region were found in samples N11-N12 presenting low values, around $8 \mathrm{mg} / \mathrm{g}$, or sample $\mathrm{N} 13$ where pinocembrin was even below the quantification limit. Other samples such as $\mathrm{CI} 1-\mathrm{CI} 3$, S2-S4 or MI-M2 revealed also a poor content in flavanones.

The second class of flavonoids observed in high quantities in the north $(\mathrm{N})$, central coast $(\mathrm{CC})$ and in Azores $(\mathrm{A})$ propolis were the flavonoid esters, representing approximately $25 \%$ of the total flavonoid content. Some propolis samples in the north $(\mathrm{N})$ reveal amounts of the pinobanksin esters up to $150 \mathrm{mg} / \mathrm{g}$ of extract. For
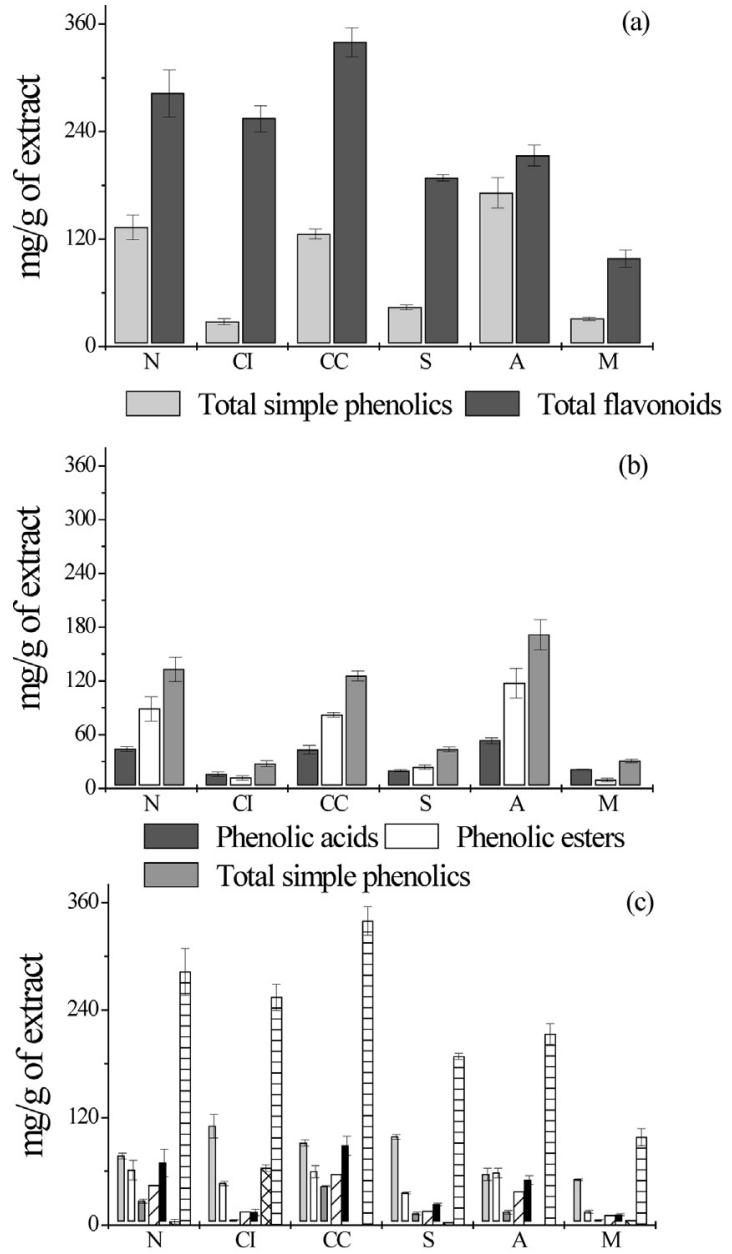

Flavonols $\square$ Flavones $\square$ Dihydroflavonols $\square 77$ Flavanone Flavonoid esters $X \times$ Flavonoid glycosides $\rightleftarrows$ Total flavonoids

Fig. 3. Composition for the main classes of phenolic compound present in propolis samples from: north $(\mathrm{N})$, central interior $(\mathrm{CI})$, central coast $(\mathrm{CC})$, south $(\mathrm{S})$, Azores Archipelago (A) and Madeira Island (M) regions. (a) Total simple phenolics and total flavonoids. (b) Phenolic acids, phenolic esters and total simple phenolics. (c) Flavonols, flavones, dihydroflavonols, flavanones, flavonoid esters, flavonoid glycosides and total flavonoids.

other side, in the south $(\mathrm{S})$ and in Madeira (M) the content of these ester derivatives in propolis was low and sometimes even absent (Table 3).

Portuguese propolis has been recently described to present an uncommon composition rich in flavonoid glycosides (Falcão et al., 2013). This was detected in samples N11-N13 from north, CI1 from central interior, S4 from south and M2 from Madeira Island. On those, fourteen flavonoid glycosides, mainly quercetin and kaempferol glycosides were identified. Due to the complexity of the resulting chromatograms and the proximity in the retention time, the flavonoid glycosides were quantified as one. Sample CI1 from the central interior (Guarda) is clearly different from all the others with almost $228 \mathrm{mg} / \mathrm{g}$, representing $43 \%$ of the flavonoids in this sample and contribute to the highest value observed in all the samples under study $(535 \mathrm{mg} / \mathrm{g})$. The other propolis samples with flavonoid glycosides had a much lower content, between 12 and $23 \mathrm{mg} / \mathrm{g}$ (Table 3).

As described, not all the samples within a region present the same phenolic profile or content. The statistic analysis with hierarchical cluster (Fig. 4), clearly identified three groups and an outlier sample (CI1): the first group contain most of the samples 


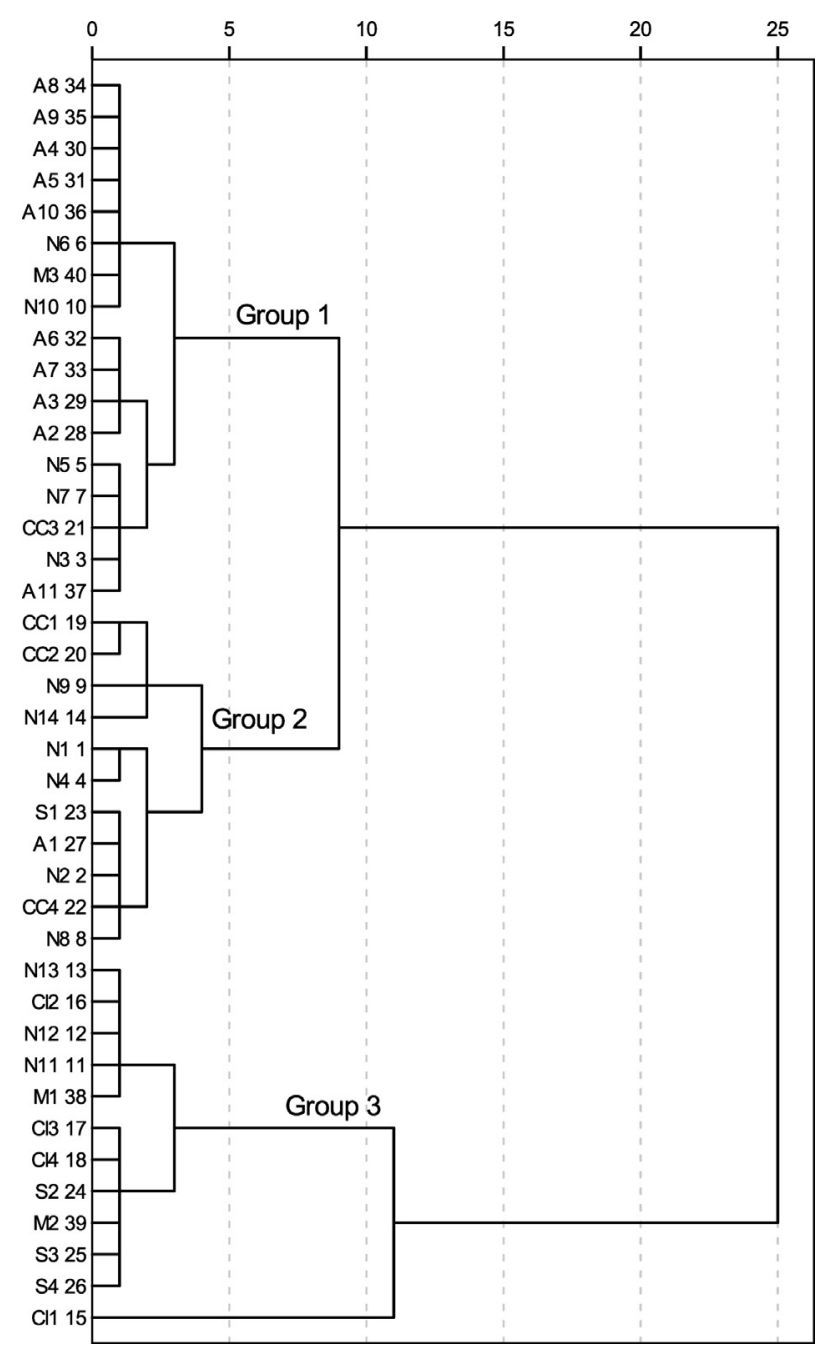

Fig.4. Dendrogram obtained by hierarchical cluster analysis of the propolis phenolic content from: north $(\mathrm{N})$, central interior $(\mathrm{CI})$, central coast $(\mathrm{CC})$, south $(\mathrm{S})$, Azores Archipelago (A) and Madeira island (M).

from Azores (A), five samples from the north $(\mathrm{N})$, one sample from Madeira (M) and other from center coast; the second group is mainly composed by the north (N) and central coast (CC) samples; the third group contains most of the samples from central interior $(\mathrm{CI})$, south $(\mathrm{S})$ and Madeira $(\mathrm{M})$, and include samples N11-N13 from the north. This later group is distinctive from the above due to the low content on simple phenolics and the presence of flavonoid glycosides. The distinction between the first two groups is not as evident and relies in the total amount of flavonoids: group 2 is richer, particularly in respect to flavonols and dihydroflavonols. These differences can only be explained by the phyto-diversity provided within those Portuguese regions.

\subsection{Phenolic quantification in the plant sources - botanical origin}

The ethanolic extracts of Populus $x$ Canadensis, male (PF) and female (PM), showed a comparable composition of simple phenolics, with higher values for the esters derivatives, up to $65 \mathrm{mg} / \mathrm{g}$ (approximately $70 \%$ of the total phenolics) (Table 3). Nevertheless, the total phenolic content is lower in the poplar buds than in propolis, indicating that bees collect resin from other floral sources, thus enriching the phenolic composition of the bee glue. For $C$. ladanifer exudates, phenolic acids and esters were not detected at all using this experimental approach. This class of compounds is unusual in C. ladanifer, and in the literature only vanillic acid has been described at low concentrations in the methanol: water (80:20) extract of fresh leaves (Barros et al., 2013).

The amount of flavonoids in the plant sources under study is higher in comparison with the simple phenolics. The exudates of PM were richer in flavonols $(42 \mathrm{mg} / \mathrm{g})$ and flavones $(35 \mathrm{mg} / \mathrm{g}$ of extract) whereas PF had more flavones $(47 \mathrm{mg} / \mathrm{g})$ and flavonoid esters $(42 \mathrm{mg} / \mathrm{g})$. Both poplars extracts presented a low content in dihydroflavonols, 4-6 mg/g (Table 3). These patterns are consistent with the general observation found in the propolis samples, particularly those from the north $(\mathrm{N})$, central cost $(\mathrm{CC})$ and Azores (A), however, in the latter region, the high quantity of flavones in comparison to flavonols reveal some deviation. It is interesting to notice that the exudates of female poplar reveal the same behavior, what let us consider that the variability in the poplar species around the hive could contribute to those minor differences in quantities within the phenolic composition. In fact, poplar bud exudates were reported to contain a great variety of phenolic compounds, which were dependent on the species studied (Vardar-Ünlü et al., 2008).

Through the analysis of the exudates of $C$. ladanifer, only flavonols, flavones and flavonoid glycosides were detected in a concentration of 27,11 and $27 \mathrm{mg} / \mathrm{g}$ of extract, respectively. The rich composition in kaempferol derivatives present in this plant source was also found in samples $\mathrm{Cl} 2-\mathrm{CI} 4$ from central interior and samples S2-S4 from the south, standing out the compound kaempferol-3,7-dimethyl-ether (6) which was absent in the other propolis samples with a poplar type composition.

In conclusion, the Portuguese propolis samples presented a similar phenolic composition, with significant differences found in their concentrations. The samples from north $(\mathrm{N})$, central coast (CC), Azores Archipelago (A) and sample S1, from south, revealed the higher phenolic content, up to $261 \mathrm{mg} / \mathrm{g}$ in simple phenolics and $460 \mathrm{mg} / \mathrm{g}$ in flavonoids, with a profile similar to the one observed in the bud exudates extracts of Populus $x$ Canadensis. The other samples, which include propolis N11-N13 from north regions, $\mathrm{Cl} 2-\mathrm{CI} 3$ from central interior, S2-S4 from south and samples M1-M2 from Madeira Island presented a poor composition in the generality of the phenolic compounds, with less than $44 \mathrm{mg} / \mathrm{g}$ of simple phenolics and $204 \mathrm{mg} / \mathrm{g}$ of flavonoids. Moreover, the phenolic profile for this propolis type is clearly different, suggesting other floral contributions for the resin rather than poplar. The phenolic constituents found in samples $\mathrm{CI} 2-\mathrm{CI} 4$ and S2-S4, rich in kaempferol derivatives, particularly kaempferol-3,7-dimethylether, resembles the $C$. ladanifer exudates. This plant source, very common in those regions, is probably the origin of the resin and the compound kaempferol-3,7-dimethyl-ether, absent in the poplar type propolis, can be regard as a marker substance for floral origin discrimination between these two types of propolis. Central interior sample, CI1, is clearly an outsider: the exclusive presence of quercetin-tetramethyl-ether, luteolin and chrysoeriol-methylether, all described before in Labiatae, particularly in Origanum spp. (Tomás-Barberán and Wollenweber, 1990; Melpomene et al., 2008), and its high content in flavonoid glycosides, $228 \mathrm{mg} / \mathrm{g}$, with a probable origin in the conifer plants (Falcão et al., 2013), confirm the difficulty to unequivocally assign the floral composition of each propolis sample.

\section{Acknowledgements}

Soraia I. Falcão thanks FCT for the PhD grant SFRH/BD/44855/2008. N. Vale thanks FCT for the Post-Doc grant SFRH/BPD/48345/2008. Thanks also to FCT for financial support provided to CIMO (PEst-OE/AGR/UI0690/2011) and to the CIQUP LC-MS facility through project CONC-REEQ/275/QUI. 
Thanks to National Federation of Portuguese Beekeepers for propolis samples.

\section{Appendix A. Supplementary data}

Supplementary data associated with this article can be found, in the online version, at http://dx.doi.org/10.1016/j.indcrop.2013. 07.021.

\section{References}

Bankova, V.S., De Castro, S.L., Marcucci, M.C., 2000. Propolis: recent advances in chemistry and plant origin. Apidologie 31, 3-15.

Bankova, V., 2005. Chemical diversity of Propolis and the problem of standardization. J Ethnopharmacol 100, 114-117.

Banskota, A.H., Tezuka, Y., Kadota, S.H., 2001. Recent progress in pharmacological research of propolis. Phytother Res $15,561-571$.

Barros, L., Dueñas, M., Alves, C.T., Silva, S., Henriques, M., Santos-Buelga, C., et al., 2013. Antifungal activity and detailed chemical characterization of Cistus ladanifer phenolic extracts. Ind Crop Prod 41, 41-45.

Bogdanov, S., Bankova, V., 2011. The propolis book (Chapter 1). Retrieved from http://www.bee-hexagon.net/en/propolis.htm [07.11.12]

Burdock, G.A., 1998. Review of the biological properties and toxicity of bee propolis (propolis). Food Chem Toxicol 36, 347-363.

Chaves, N., Ríos, J.J., Gutierrez, C., Escudero, J.C., Olías, J.M., 1998. Analysis of secreted flavonoids of Cistus ladanifer L. by high performance liquid chromatography-particle beam mass spectrometry. J Chromatogr A 799, 111-115.

Chen, C., Wu, C., Shy, H., Lin, J., 2003. Cytotoxic prenylflavanones from Taiwanese propolis. J Nat Prod 66, 503-506.

Cuyckens, F., Claeys, M., 2004. Mass spectrometry in the structural analysis of flavonoids. J Mass Spectrom 39, 1-15.
Falcão, S., Vilas-Boas, M., Estevinho, L.M., Barros, C., Domingues, M.R.M., Cardoso, S.M., 2010. Phenolic characterization of Northeast Portuguese propolis: usual and unusual compounds. Anal Bioanal Chem 396, 887-897.

Falcão, S.I., Vale, N., Gomes, P., Domingues, M.R.M., Freire, C., Cardoso, S.M., et al., 2013. Phenolic profiling of Portuguese propolis by LC-MS spectrometry: uncommon propolis rich with flavonoid glycosides. Phytochem Anal http://dx.doi.org/10.1002/pca.2412.

Greenaway, W., May, J., Whatley, F.R., 1989. Flavonoid aglycones identified by gas chromatography-mass spectrometry in bud exudate of Populus balsamifera. J Chromatogr 472, 393-400.

Isidorov, V.A., Vinogorova, V.T., 2003. GC-MS analysis of compounds extracted from buds of Populus balsamifera and Populus nigra. Z Naturforsch 58c, 335-360.

Martos, I., Cossentini, M., Ferreres, F., Tomás-Barberán, F.A., 1997. Flavonoid composition of Tunisian honeys and propolis. J Agric Food Chem 45, 2824-2829.

Melpomene, S., Grayer, R.J., Kite, G.C., Veitch, N.C., 2008. Exudate flavones and flavanones in Origanum species and their interspecific variation. Biochem Syst Eco 36, 646-654.

Popova, M.P., Chinou, I.B., Marekov, I.N., Bankova, V.S., 2009. Terpenes with antimicrobial activity from Cretan propolis. Phytochemistry 70 1262-1271.

Ribani, M., Collins, C.H., Bottoli, C.B.G., 2007. Validation of chromatographic methods: Evaluation of detection and quantification limits in the determination of impurities in omeprazole. J Chromatogr A 1156, 201-205.

Santos-Buelga, C., Garcia-Viguera, C., Tomás-Barberán, F.A., 2003. On-line identification of flavonoids by HPLC coupled to diode array detection. In: Santos-Buelga C., Williamson, G. (Eds.), Methods in polyphenols analysis. The Royal Society of Chemistry, Cambrigde, UK, pp. 92-124.

Salatino, A., Fernandes-Silva, C.C., Righi, A.A., Salatino, M.F.L., 2011. Propolis research and the chemistry of plant products. Nat Prod Rep 28, 925-936.

Tomás-Barberán, F.A., Wollenweber, E., 1990. Flavonoid aglycones from the lea surfaces of some Labiatae species. Plant Syst Evol 173, 109-118.

Vardar-Ünlü, G., Silici, S., Ünlü, M., 2008. Composition and in vitro antimicrobial activity of Populus buds and poplar-type propolis. World J Microbiol Biotechno 24, 1011-1017. 